\title{
Development of Novel, Bioresorbable, Small-Diameter Electrospun Vascular Grafts
}

Jed Johnson*, Devan Ohst, Tyler Groehl, Sarah Hetterscheidt and Matthew Jones

Nanofiber Solutions, Columbus, Ohio, USA

*Corresponding author: Jed Johnson, Nanofiber Solutions, Kinnear Road, Columbus, OH, USA, Tel: (614)-453-5877; Fax: (614)-487-3704; E-mail: Jed.Johnson@nanofibersolutions.com

Rec date: Feb 12, 2015; Acc date: Mar 21, 2015; Pub date: Mar 25, 2015

Copyright: () 2015 Johnson $\mathrm{J}$ et al. This is an open-access article distributed under the terms of the Creative Commons Attribution License, which permits unrestricted use, distribution, and reproduction in any medium, provided the original author and source are credited.

\begin{abstract}
This study proposes a production method capable of producing vascular grafts from fully synthetic, resorbable polymers that both meet basic minimum mechanical requirements for potential vascular grafts, and have a compliance similar to that of the intended vasculature being replaced. All of the electrospun vascular grafts in this work meet the minimum mechanical requirements for compliance, burst pressure, and suture retention strength, and could be potential candidates for off-the-shelf tissue engineered vascular grafts. Each polymer investigated in this paper has FDA approval for medical use and has been shown to be successful in various tissue engineering applications. Only recently has an electrospun small-diameter graft been fabricated with compliance and burst pressure greater than that of the human saphenous vein. We show a significant advancement in burst pressure, compliance, and suture retention strength in the novel electrospun grafts presented in this work which demonstrates the potential use of these tissue engineered vascular grafts for coronary artery bypass graft and other smalldiameter graft indications.
\end{abstract}

Keywords: Nanofibers; Vascular graft; Conduit; Shunt; Electrospinning; Tissue engineering

\section{Introduction}

Cardiovascular disease is one of the leading causes of death in western countries. According to the American Heart Association, almost 3 million procedures associated with the heart or blood vessels are performed in the United States each year, with over \$25 billion spent on 400,000 coronary artery bypass graft (CABG) procedures [1-4]. Success has been found in creating vascular grafts with diameters greater than $6 \mathrm{~mm}$ because their massive blood flow allows for them to overcome native thrombogenicity in the graft material [5]. However, there is still a great demand for small diameter $(<6 \mathrm{~mm})$ vascular grafts for vessels such as the coronary artery. Autologous vein, specifically the saphenous vein, remains the gold standard of vascular replacement, but its use is restricted in up to $20 \%$ of patients due to comorbidities [6] and the replicability of grafts from older donors is limited $[7,8]$.

The alternative to an autologous vein is the use of synthetic grafts made from either expanded polytetrafluoroethylene (ePTFE) or polyethylene terephthalate (PET), also known as Gore-Tex ${ }^{\mathrm{TM}}$ (PTFE) or Dacron ${ }^{\mathrm{TM}}$ (PET), respectively. In circumstances where autologous sources are in limited supply, such as combat wound scenarios [9], these synthetic grafts are appealing because they are readily available and can be used directly off-the-shelf. The use of these synthetic grafts has a long history, but their problems are well known. Infection, thrombosis, compliance mismatch, and the inability to match biomechanical properties of the native vasculature are problems with these synthetics $[8,10-12]$. Therefore, research is being done on new alternatives to ePTFE and PET for small caliber vascular replacements.
Since the greatest clinical need for vascular replacements is for CABG, mechanical properties of the vascular graft such as compliance and burst pressure are critical. The compliance mismatch between the graft and the native vessel disrupts blood flow resulting in zones of recirculation, flow separation, and low wall shear stress [13]. Low wall shear stress initiates the release of vasoactive substances, gene activation, protein expression, and cytoskeletal rearrangement that stimulate neointimal hyperplasia [14]. This is seen as a cause of failure in both autologous and prosthetic bypass grafts, though saphenous vein grafts also suffer from stenosis at sites away from the anastomosis [15].

Tissue engineering offers an alternative approach to existing vascular repair methods. Tissue engineering was first proposed in the 1980 's, with the general idea that biodegradable scaffolds could be used for cell attachment and proliferation. These scaffolds, when implanted into the body, can help to facilitate the regeneration of the native tissue. The formation of neotissue is critical to the success of a tissue engineered vascular graft (TEVG), the most crucial being a fully formed endothelium. The ideal TEVG has high biocompatibility, matching compliance to the native vessel, high suture retention strength and burst pressure, non-thrombogenic, resistance to neointimal hyperplasia, resistance to infection, easy to suture, and easily manufactured [16]. Matching the native vessel compliance is arguably the most critical attribute and requires the ability to finely tune the mechanical properties of the graft to that of the native vasculature.

There are several tissue engineering approaches being taken to address this challenge. One approach taken by Cytograft ${ }^{\mathrm{TM}}$ is a cell sheet method, which bypasses the use of biodegradable polymer scaffolds. In this approach, fibroblasts are cultured in a culture flask with a high sodium ascorbate environment to promote the formation of an extracellular matrix. This cell sheet is then matured and wrapped 
around a Teflon-coated, stainless-steel temporary support tube and continued to mature for at least 10 weeks [2]. Although the Cytograft ${ }^{\mathrm{TM}}$ cell sheets have found some success in clinical trials [17], the manufacturing time of the cell sheet vascular grafts can be upwards of 36-40 weeks. This raises concerns about the cost to produce these grafts and the ability to be available off-the-shelf. Although the Cytograft ${ }^{\mathrm{TM}}$ graft has be shown to match compliance of the saphenous vein, there is compliance mismatch when compared to the coronary artery [2].

Another approach, used by Humacyte ${ }^{\mathrm{TM}}$, is to grow vascular smooth muscle cells on a biodegradable polyglycolic acid (PGA) scaffold in vitro then decellularize the cultured blood vessel to produce a cell-free vascular graft [18]. Ideally, this leaves behind a new scaffold comprised entirely of the extracellular matrix left behind by the decellularized vessel presumably without risk of an immunogenic response [19]. The inherent risk is that the cell-based material is not completely removed from the extracellular matrix leaving the possibility of an immunogenic response. Additionally, the manufacturing time of the Humacyte ${ }^{\mathrm{TM}}$ vascular graft is at least 10 weeks, raising concerns about the cost to produce these grafts and ability to be available off-the-shelf [18].

Another widely used and successful approach to tissue engineering is the use of electrospun nanofiber scaffolds. These fibers mimic the native extracellular matrix architecture and have been shown to be useful in producing small caliber vascular graft replacements [12,20-22]. These grafts can be created from various polymers and can be co-spun with natural polymers and peptides [21,23-25]. These grafts retain the off-the-shelf appeal of the traditional synthetic grafts, but are designed to support the formation of neotissue and thus avoid the problems of ePTFE and PET because of their improved biocompatibility. Additionally, the burst pressures of these electrospun grafts can be customized by adjusting the electrospinning parameters and have been shown to be comparable to that of the native vasculature [26]. It is also possible to produce grafts with various fiber sizes and pore sizes by altering the polymer/solvent combination and the concentration of the polymer solute. By altering these electrospinning parameters, the fibers can be given many different biomechanical and biochemical properties which could help with matching the native vasculature compliance and in the formation of neotissue. Co-spinning, co-spraying, coaxial setups, micro-patterning, and use of hydrogels can also be implemented in order to increase the biocompatibility of these scaffolds $[27,28]$.

This paper will focus on the biomechanical properties of various types of synthetic, fully resorbable polymers that have been electrospun into scaffolds for use in TEVGs. Each of these polymers has FDA approval for medical use and has been shown to be successful in various tissue engineering applications. Only recently has an electrospun small-diameter graft been fabricated with compliance and burst pressure greater than that of saphenous vein [29]. We show a significant advancement in burst pressure, compliance, and suture retention strength (SRS) in the novel electrospun grafts presented in this work. In an attempt to establish a baseline characterization and comparison in electrospun grafts to commercially available grafts, we also show the mechanical properties from a variety of natural and synthetic grafts. As the research community continues to build a critical mass of knowledge in the design and use of electrospun TEVGs, we hope to translate this promising technology to the clinic and improve patient care across the world.

\section{Materials and Methods}

\section{Polymer Solution Preparation}

Several different resorbable polymers were used to fabricate the TEVGs as shown in Table 1. Polymer solutions were prepared for electrospinning by dissolving the polymer in hexafluro-Isopropanol (HFIP) (Oakwood Chemicals). PCL/CS was prepared differently using a blend of HFIP and Acetic Acid (AA) (Sigma-Aldrich) at a weight ratio of 9:1. Each solution was mixed for at least 24 hours at room temperature before electrospinning to ensure homogeneity.

\begin{tabular}{|c|c|c|c|c|}
\hline Polymer & Abbreviation & Manufacturer & $\begin{array}{l}\text { Ratio } \\
\text { polymers }\end{array}$ & wt $\%$ of polymer in solution \\
\hline Polycaprolactone & PCL & Sigma-Aldrich & - & 5 \\
\hline Polycaprolactone and Chitosan blend & PCL/CS & Sigma-Aldrich & $20: 1$ & 3.15 \\
\hline Polydioxanone & PDO & Evonik & - & 7 \\
\hline Polyglycolic acid & PGA & Foryou & - & 10 \\
\hline Poly (lactic-co-caprolactone) & PLCL & Purac & $70: 30$ & 5 \\
\hline Poly (lactic-co-glycolic acid) & PLGA8218 & Purac & $82: 18$ & 6 \\
\hline Poly (lactic-co-glycolic acid) & PLGA1090 & Purac & 10:90 & 8 \\
\hline Poly-L-lactide & PLLA & Goodfellow & - & 8 \\
\hline
\end{tabular}

Table 1: Polymers used in each solution and their solution weight percent.

\section{Electrospinning}

A 20cc syringe (Becton-Dickenson, USA), with a 20-gauge needle tip, was filled with the polymer solution. The $20 \mathrm{cc}$ syringe was secured in a syringe pump (Harvard Apparatus, USA), and positioned to achieve a tip to collector distance of $20 \mathrm{~cm}$. The solution was ejected at
$5 \mathrm{~mL} / \mathrm{hr}$ with an applied voltage between $+9 \mathrm{kV}$ and $+20 \mathrm{kV}$ on the needle and between $-1 \mathrm{kV}$ and $-4 \mathrm{kV}$ on the collector, such that a stable Taylor Cone was established. Each polymer solution was electrospun onto a cylindrical mandrel rotating at $15 \mathrm{rpm}$ with an outer diameter of $6 \mathrm{~mm}$, until the fiber deposition generated a vascular graft with a 
Page 3 of 7

wall thickness of $650 \mu \mathrm{m} \pm 65 \mu \mathrm{m}$. The vascular grafts were soaked in $100 \%$ ethanol and removed from the mandrel for characterization.

\section{Mechanical Testing}

Data for the compliance, burst pressure, and SRS were acquired using a universal testing machine (MTS Systems Corporation) fitted with a $50 \mathrm{lb}$ load cell with a force resolution of $10^{-4}$ pounds and a linear displacement resolution of $10^{-8}$ inches. Compliance testing was performed using a displacement velocity of $1.5 \mathrm{~mm}$ per minute and acquisition rate of 4 data points per second utilizing Laplace's Law $[30,31]$ to correlate linear force and displacement to compliance. Burst pressure testing was performed using a displacement velocity of 50 $\mathrm{mm}$ per minute and acquisition rate of 4 data points per second utilizing Laplace's Law [31,32] to correlate linear force and displacement to burst pressure.

\section{Linear Tensile Mechanical Testing}

Using a scalpel, the vascular graft was cut perpendicular to the longitudinal axis to form a cylindrical sample with a length of no less than the internal diameter of the graft. The cylindrical sample was then placed around two steel rods, one rod was attached to the load frame base of the universal testing machine and the other to the load cell. The sample was strained perpendicular to the longitudinal axis. With this test setup and assumptions [30, 31], we assume that the circumference $(\mathrm{C})$ is increased by twice the displacement $(\delta)$. This is displayed in Equation 1 with $\mathrm{D}_{\mathrm{O}}$ being the original diameter.

$\pi D_{O}+2 \delta=C a$-----Equation 1

Assuming that a fractional change in circumference is equal to a fractional change in the diameter, we can use Equation 2. This equation relates systolic circumference $\left(\mathrm{C}_{S}\right)$ and diastolic circumference $\left(C_{D}\right)$ to systolic diameter $\left(D_{S}\right)$ and diastolic diameter $\left(D_{D}\right)$.

$$
\frac{C S}{C D}=\frac{D S}{D D}---- \text { Equation } 2
$$

Equation 3 substitutes the systolic and diastolic forms of Equation 1 into Equation 2.

$$
\frac{\pi D O+2 \delta S}{\pi D O+2 \delta D}=\frac{D S}{D D}
$$

The calculation for compliance $\left(\mathrm{C}_{\%}\right)$ (Equation 4) can be simplified where $P_{S}$ represents the systolic pressure and $P_{D}$ represents the diastolic pressure.

$$
C \%=\frac{\frac{D S-D D}{D D}}{P S-P D}{ }^{4} 10^{4}=\frac{\frac{D S}{D D}-\frac{D D}{D D}}{P S-P D} * 10^{4}=\frac{\frac{D S}{D D}-1}{P S-P D}{ }^{*} 10^{4} \text {----Equation } 4
$$

Substituting Equation 3 into Equation 4 will give us Equation 5.

$$
C \%=\frac{\frac{\pi D O+2 \delta S}{\pi D O+2 \delta D}-1}{P S-P D} * 10^{4} \text {-----Equation } 5
$$

The pressure within the vascular graft can be calculated using the data from a universal testing machine and Equation 6 where $P$ is pressure, $\mathrm{F}$ is the force perpendicular to the longitudinal axis, and $\mathrm{l}$ is the length of the graft. To represent native blood pressures, systolic and diastolic pressures of $120 \mathrm{mmHg}$ and $80 \mathrm{mmHg}$, respectively, were used.

$$
P=\frac{F}{D O I} \text {-----Equation } 6
$$

Substituting the systolic and diastolic forms of Equation 6 into Equation 5 yields Equation 7. With this equation and the data received from the universal testing machine the compliance was calculated.

$$
C \%=\frac{\frac{\pi D O+2 \delta S}{\pi D O+2 \delta D}-1}{\frac{F S}{D O l}-\frac{F D}{D O l}} * 10^{4} \text {-----Equation } 7
$$

Using the universal testing machine, the vascular graft was cut perpendicular to the longitudinal axis to form a cylindrical sample with a length of no less than the internal diameter of the graft. The cylindrical sample was then placed around two steel rods, one rod was attached to the load frame base of the universal testing machine and the other to the load cell. The sample was strained perpendicular to the longitudinal axis until failure. With this test setup and assumptions $[31,32]$, the burst pressure $\left(\mathrm{P}_{\mathrm{B}}\right)$ was determined using wall thickness $\left(\mathrm{T}_{\mathrm{W}}\right)$, ultimate tensile strength (UTS) $\left(\sigma_{\mathrm{ts}}\right)$, and the initial internal diameter $\left(\mathrm{D}_{\mathrm{O}}\right)$. (Equation 8)

$$
P_{B}=\frac{2^{\star} T W^{\star} \sigma t s}{D O} \text {-----Equation } 8
$$

\section{Suture Retention Strength}

SRS data was collected using a universal testing machine setup according to ISO 7198. A 2-0 catgut suture was pierced through the wall of the scaffold $2.0 \mathrm{~mm}$ from the edge and tied to form a loop. The non-sutured end of the scaffold and the suture loop were each attached to separate clamps in the universal testing machine and the suture pulled at $50 \mathrm{~mm}$ per minute with an acquisition rate of 4 data points per second until the thread was pulled through the scaffold.

\section{Catheter Balloon Mechanical Testing}

An alternative method to measure the burst pressure and compliance of the vascular grafts was also used to characterize the electrospun grafts in this paper and outlined in ISO 7198:1998. A 60cc syringe (Becton-Dickenson, USA) was filled with water and placed in a syringe pump (KD Scientific, USA). The syringe pump was set to a constant flow rate of $5 \mathrm{~mL} / \mathrm{min}$. Surgical tubing was connected to the $60 \mathrm{~mL}$ syringe, and passed through a pressure transducer (Honeywell). The end of the surgical tubing was connected to a FR18 pediatric Foley catheter (Coloplast, Denmark).

A $2.5 \mathrm{~cm}$ long section of the vascular graft was positioned directly over the catheter balloon. The vascular graft section was centered in the field of view of a High Accuracy CCD Micrometer (Keyence, USA). Pressure and scaffold diameter readings were taken using Labview 2010 software and recorded four times per second. Testing was stopped at the point of failure of the scaffold or when the pressure reached 30 psi due to physical constraints of the catheter, tubing connections, and syringe pump.

Compliance $\left(\mathrm{C}_{\%}\right)$ for this test was calculated using the compliance equation (Equation 4) where $P_{S}$ is the systolic pressure, $P_{D}$ is the diastolic pressure, $D_{S}$ is the diameter at the systolic pressure, and $D_{D}$ is the diameter at the diastolic pressure.

$$
C \%=\frac{\frac{D S-D D}{D D}}{P S-P D}{ }^{4}=\frac{\frac{D S}{D D}-\frac{D D}{D D}}{P S-P D} 0^{4} 10^{4}=\frac{\frac{D S}{D D}-1}{P S-P D}{ }^{*} 10^{4} \text {----Equation } 4
$$




\section{Results}

\section{Compliance}

Figure 1 provides a visual comparison for the compliance values of the TEVGs to commercially available grafts, the carotid artery and saphenous vein. The PLCL graft exhibited the highest value for compliance at $8.2 \% / \mathrm{mmHg}$, while the PDO graft held a value of $5.7 \% /$ $\mathrm{mmHg}$. Both of these electrospun polymer grafts displayed a higher compliance value than the human carotid artery, with an average compliance of $5.4 \% / \mathrm{mmHg}$. The PGA graft exhibited a slightly lower compliance than the carotid artery, at $4.8 \% / \mathrm{mmHg}$. The human coronary artery, PLLA, silk fibroin, Cytograft ${ }^{\mathrm{TM}}$, PCL, and PCL/CS grafts all displayed similar compliance values ranging from 3.2-3.8\%/ mmHg. The bovine heterograft and PLGA8218 graft exhibited even lower compliances at 2.6 and $2.5 \% / \mathrm{mmHg}$, respectively. The electrospun polymer graft that demonstrated the lowest compliance was PLGA1090 at $1.9 \% / \mathrm{mmHg}$. The Dacron knitted graft and the IMPRA ePTFE graft were even less compliant at 1.9 and $1.6 \% / \mathrm{mmHg}$, respectively. The human saphenous vein had the lowest compliance of all at $1.1 \% / \mathrm{mmHg}$.

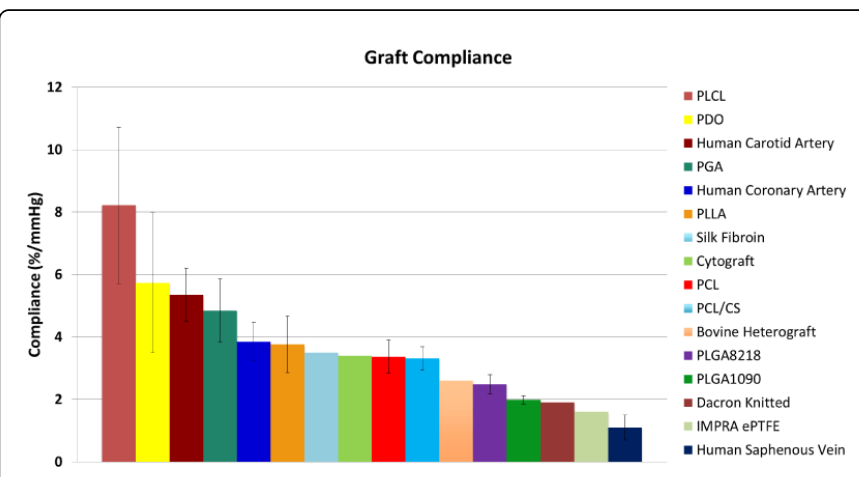

Figure 1: Compliance values for the electrospun vascular grafts, commercially available synthetic grafts, bovine heterograft, silk fibroin graft, Cytograft ${ }^{\mathrm{TM}}$, human carotid artery, human coronary artery, and human saphenous vein [1-3]. Error bars represent standard deviation when available.

\section{Burst Pressure}

Burst pressure values for the electrospun grafts, commercially available grafts, human carotid artery and human saphenous vein are displayed in Figure 2. The PLGA1090 graft had the highest burst pressure at 3.3 MPa followed closely by the Dacron knitted graft with a burst pressure of $3.2 \mathrm{MPa}$. The PLCL graft had a burst pressure strength of $2.5 \mathrm{MPa}$, while the PLGA8218 and PCL/CS grafts displayed lower burst pressure strengths of 2.2 and 1.9 MPa, respectively. Subsequently, the PLLA graft exhibited a burst pressure strength of 1.8 $\mathrm{MPa}$ and the PGA graft was $1.5 \mathrm{MPa}$. The electrospun grafts with the lowest burst pressure strengths were PDO and PCL, at $0.9 \mathrm{MPa}$ and 0.8 $\mathrm{MPa}$. The human carotid artery, human saphenous vein, Cytograft ${ }^{\mathrm{TM}}$, IMPRA ePTFE graft and silk fibroin graft all displayed significantly lower burst pressure strengths when compared to our electrospun grafts, with values ranging from $0.1 \mathrm{MPa}$ to $0.5 \mathrm{MPa}$.

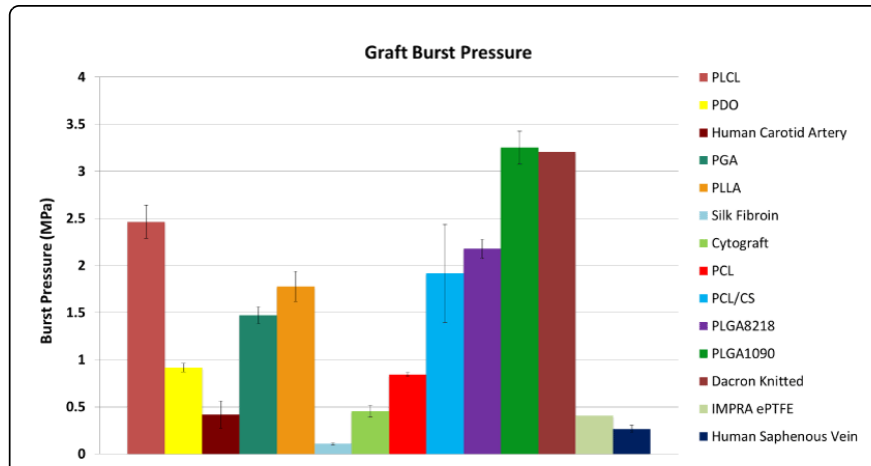

Figure 2: Burst pressure values for the electrospun vascular grafts, commercially available synthetic grafts, silk fibroin graft, Cytograft $^{\mathrm{TM}}$, human carotid artery, and human saphenous vein $[1,2]$. Error bars represent standard deviation when available.

\section{Suture Retention Strength}

SRS values, measured in grams, are displayed in Figure 3. The Dacron knitted graft exhibited the highest SRS value when compared to the electrospun TEVGs, commercially available grafts, human carotid artery and human saphenous vein, with a value of 3,270 g. The electrospun graft with the highest SRS was PLLA at 1,022 $\mathrm{g}$ followed by the PLGA1090 and PLGA8218 grafts with values of $997 \mathrm{~g}$ and $995 \mathrm{~g}$, respectively. The PGA, PDO, and PCL grafts exhibited values in the middle of the data set, ranging from $674 \mathrm{~g}$ to $748 \mathrm{~g}$.

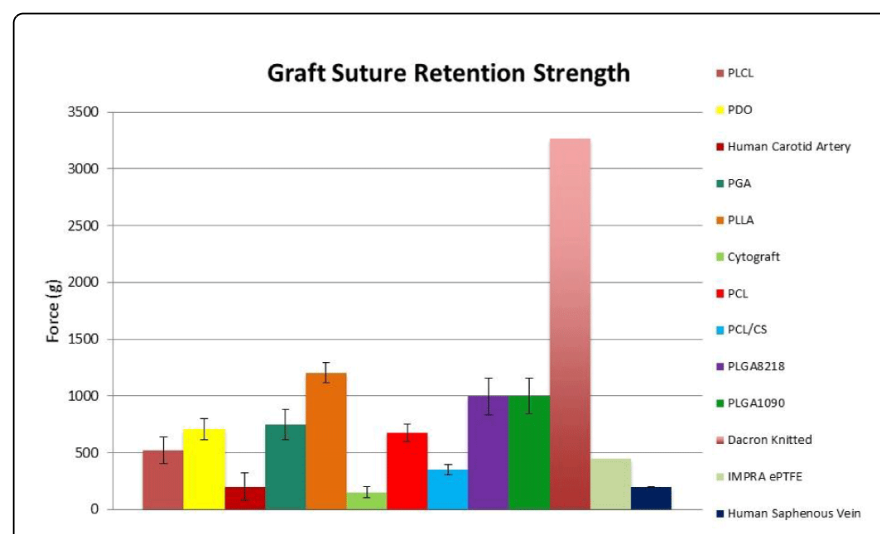

Figure 3: Suture retention strength values for the electrospun vascular grafts, commercially available synthetic grafts, CytograftTM, human carotid artery, and human saphenous vein [1, 2]. Error bars represent standard deviation when available.

The PLCL graft followed next with a SRS of $521 \mathrm{~g}$. The IMPRA ePTFE graft had a lower SRS of $451 \mathrm{~g}$ and the PCL/CS graft displayed the lowest SRS for the electrospun grafts at $355 \mathrm{~g}$. The human carotid artery, human saphenous vein, and Cytograft ${ }^{\mathrm{TM}}$ exhibited the lowest SRS values of the data set ranging from $152 \mathrm{~g}$ to $200 \mathrm{~g}$. 


\section{Compliance and Burst Pressure as a Function of Wall Thickness}

To investigate the potential effects of sidewall thickness on the graft compliance and burst pressure, we electrospun PCL grafts of varying sidewall thicknesses and tested their mechanical properties as described previously. As shown in Figure 4A, compliance remains relatively constant once the graft sidewall thickness reaches a thickness of approximately $400 \mu \mathrm{m}$. For sidewall thicknesses of $400 \mu \mathrm{m}$ to 1,000 $\mu \mathrm{m}$, the compliance remains steady within a range of $2-4 \% / \mathrm{mmHg}$. However, it is visible that at smaller sidewall thickness values, the PCL grafts exhibit a large variance in compliance measurements ranging from $2-11 \% / \mathrm{mmHg}$.

Figure $4 \mathrm{~B}$ illustrates that the burst pressure increases as the graft sidewall thickness increases. For the PCL grafts with a sidewall thickness ranging from $200-1,000 \mu \mathrm{m}$, the burst pressure values increase in a linear fashion from 0.6 $\mathrm{MPa}$ to $2.9 \mathrm{MPa}$. This linear relationship is displayed by the best fit line applied to the data points in a scatter plot.

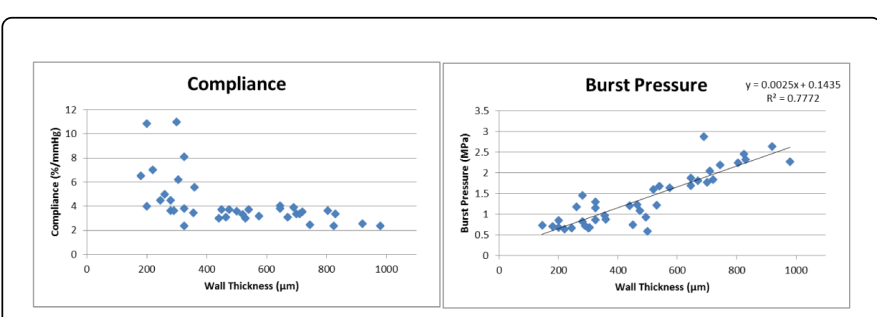

Figure 4: Compliance (A) and Burst Pressure (B) values for electrospun PCL grafts versus wall thickness.

\section{Burst Pressure Method Comparison}

To investigate any potential difference in the burst pressure values obtained utilizing the linear tensile approach with Equation 8 versus those values obtained with the catheter balloon method, we tested five electrospun PCL samples with the linear tensile method and five electrospun PCL samples with the catheter balloon method of identical wall thicknesses. The results are shown in Figure 5, where the linear tensile method averaged a $30 \%$ higher burst pressure compared to the catheter balloon method.

\section{Discussion}

Of the data found on the compliance of commercially available vascular grafts, none showed a compliance that matched that of the human carotid artery. The average compliance of native human carotid artery $(5.4 \% / \mathrm{mmHg})$ was approximately $2 \mathrm{x}$ greater than the most compliant commercially available vascular graft (bovine heterograft $2.6 \% / \mathrm{mmHg}$ ) included in this study (Figure 1). Similarly, the average compliance of human coronary artery $(3.8 \% / \mathrm{mmHg})$ was approximately $1.5 \mathrm{x}$ of the most compliant commercially available graft. This compliance mismatch may be a major contributing factor in the poor clinical performance of these grafts. In this study, multiple types of biodegradable, synthetic electrospun grafts were fabricated that had compliance values near that of the human carotid and coronary arteries. The PDO and PGA grafts had a compliance of $5.7 \pm$ $2.2 \% / \mathrm{mmHg}$ and $4.9 \pm 1.0 \% / \mathrm{mmHg}$, respectively, similar to that of the human carotid artery with a compliance of $5.4 \pm 0.9 \% / \mathrm{mmHg}$ (Figure
1). The PLLA graft had a compliance of $3.8 \pm 0.9 \% / \mathrm{mmHg}$, similar to that of the human coronary artery with a compliance of $3.9 \pm 0.6 \%$ / $\mathrm{mmHg}$.

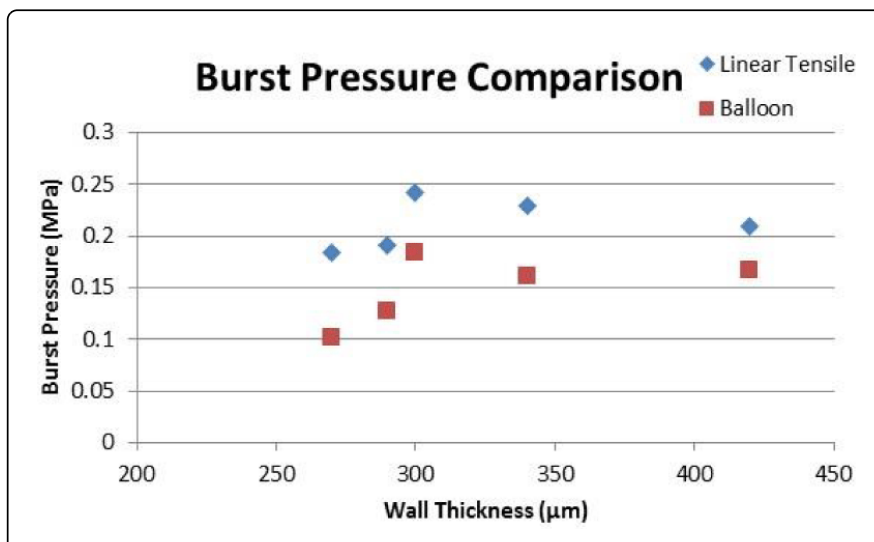

Figure 5: Comparison of burst pressure values of electrospun PCL grafts for the linear tensile method and the catheter balloon method.

Other polymers investigated in this paper may match the compliance of the desired vasculature by manipulating the wall thickness of the graft. For example, the wall thickness of the PLGA1090 graft could be decreased to increase the compliance since the burst pressure value is relatively high. While most of the concern in optimizing the mechanical properties of vascular grafts is focused on the choice of the polymer and the method of production, this work illustrates the significant importance of the wall thickness on the mechanical properties of the graft. The differences in the mechanical properties based on dimensional changes have been shown to be greater than the differences in mechanical properties between polymers. This leads to the idea that when characterizing the mechanical properties of potential vascular grafts, the dimensions of the grafts being implanted in vivo must match the dimensions of the grafts for mechanical characterization, otherwise there is a potential for significant differences in the mechanical properties that could lead to complications in vivo.

All of the burst pressures of the tested electrospun TEVG compositions are above those seen in native human saphenous veins and carotid arteries (Figure 2). This further supports the notion of adjusting the sidewall thickness to achieve the desired graft compliance, as long as the minimum burst pressure is achieved.

All of the electrospun TEVGs in this study surpassed the $2 \mathrm{~N}$ or 204 $\mathrm{g}$ standard minimum SRS recommended for potential vascular prosthetics [33] (Figure 3). While the SRS may not be as critical for clinical performance as the burst pressure and compliance, the duration of the surgery and risk of complications to the patient may increase if the sutures tear through the vascular graft during anastomosis in vivo.

Investigating the effect of wall thickness on the compliance of the vascular graft reveals a significant change in the compliance values when the wall thickness was below $400 \mu \mathrm{m}$ as compared to grafts with a wall thickness greater than $400 \mu \mathrm{m}$ (Figure $4 \mathrm{~A}$ ). When the graft wall thickness was less than $400 \mu \mathrm{m}$, there was a significant increase in the variability of compliance values and an overall average increase in the compliance values. This abrupt change in mechanical behavior is 
indicative of a change in how the nanofibers within the graft react to the applied stresses. The thin walled electrospun grafts have a higher percentage of fibers exposed to the outer surface (i.e. no surrounding fibers) than the thicker grafts, allowing for increased fiber mobility within the sidewall which allows the fibers to re-orient in response to the applied stresses. After a certain thickness threshold is reached, in this case approximately $400 \mu \mathrm{m}$, the percentage of fibers exposed to the outer surface (i.e. no surrounding fibers) becomes negligible and the fiber motion is restricted which results in a less compliant vascular graft.

The relationship between wall thickness and burst pressure of the vascular graft is evident (Figure 4B). As expected, a strong linear correlation can be seen between the burst pressure of the graft and the wall thickness of the graft. As the wall thickness increases, more fibers are present which results in more material present to bear the applied pressure. The greater number of fibers also increases the chance for the fibers to re-orient themselves in the direction of the loading $[34,35]$.

Comparison of the two methods, the linear tensile method using Equation 8 and the catheter balloon method, for determining the burst pressure of a small diameter vascular graft revealed a significant difference in the values of the grafts (Figure 5). The linear tensile method was shown to have average burst pressures approximately $30 \%$ higher than similar grafts tested using the catheter balloon based method. The difference in burst pressure is likely due to differences in the mobility of the individual fibers in the nanofiber mesh. Previous studies have shown that balloon based methods of burst pressure determination result in artificially lower burst pressures due to the pinning of fibers, which prevents the fibers from translating and reorienting in the direction of loading $[29,34,35]$. Visual observation of the failure of the electrospun grafts during the catheter balloon burst pressure testing method demonstrated that the pressurized balloon squeezes and compresses the sidewall of the nanofiber mesh, preventing the nanofibers from re-orienting as the diameter increases and initiates failure of the graft in a very localized region. In contrast, visual observation of the failure of the grafts during the linear tensile method showed no signs of localized failure. Although the catheter balloon method of mechanical testing may be more representative of the pressures experienced by the graft in vivo, the limitations in the sensitivity of the pressure transducer at lower pressures and the limitation of the strength of the catheter balloon itself at maximum pressure limits the usefulness of the catheter balloon method in the determination of the compliance and burst pressure of these small diameter vascular grafts.

\section{Conclusions}

All of the electrospun vascular grafts in this work meet the minimum mechanical requirements for compliance, burst pressure and SRS, and could be potential candidates for off-the-shelf tissue engineered vascular grafts. Each of the polymers investigated in this paper has FDA approval for medical use and has been shown to be successful in various tissue engineering applications. Only recently has an electrospun small diameter graft been fabricated with compliance and burst pressure greater than that of a human saphenous vein. We show a significant advancement in burst pressure, compliance and suture retention strength in the novel electrospun tissue engineered grafts presented in this work. Further in vivo testing will be necessary to determine the degradation rate and remodeling profile for each of these TEVGs before they can be translated to the clinic.

\section{References}

1. Marelli B, Alessandrino A, Farè S, Freddi G, Mantovani D, et al. (2010) Compliant electrospun silk fibroin tubes for small vessel bypass grafting. Acta Biomater 6: 4019-4026.

2. L'Heureux N, Dusserre N, Konig G, Victor B, Keire P, et al. (2006) Human tissue-engineered blood vessels for adult arterial revascularization. Nat Med 12:361-365.

3. Shaw JA, Kingwell BA, Walton AS, Cameron JD, Pillay P, et al. (2002) Determinants of coronary artery compliance in subjects with and without angiographic coronary artery disease. J Am Coll Cardiol 39: 1637-1643.

4. Roger VL, Go AS, Lloyd-Jones DM, Adams RJ, Berry JD, et al. (2011) Heart disease and stroke statistics--2011 update: a report from the American Heart Association. Circulation 123: e18-18e209.

5. Vacanti JP, Langer R (1999) Tissue engineering: the design and fabrication of living replacement devices for surgical reconstruction and transplantation. Lancet 354:SI32-SI34.

6. Goldman S, Sethi GK, Holman W, Thai H, Mc Falls E, et al. (2011) Radial artery grafts vs saphenous vein grafts in coronary artery bypass surgery: a randomized trial. JAMA 305: 167-174.

7. McAllister TN, Maruszewski M, Garrido SA, Wystrychowski W, Dusserre N, et al. (2009) Effectiveness of haemodialysis access with an autologous tissue-engineered vascular graft: a multicentre cohort study. Lancet 373: 1440-1446.

8. Peck M, Gebhart D, Dusserre N, McAllister TN, L'Heureux N (2012) The Evolution of Vascular Tissue Engineering and Current State of the Art. Cells Tissues Organs 195:144-58.

9. Vertrees A, Fox CJ, Quan RW, Cox MW, Adams ED, et al.(2009) The Use of Prosthetic Grafts in Complex Military Vascular Trauma: A Limb Salvage Strategy for Patients With Severely Limited Autologous Conduit. J Trauma66:980-983.

10. Zilla P, Bezuidenhout D, Human P (2007) Prosthetic vascular grafts: wrong models, wrong questions and no healing. Biomaterials 28: 5009-5027.

11. Tomizawa Y, Noishiki Y (1995) Regarding "Evaluation and performance standards for arterial prostheses". J Vasc Surg 21: 542-543.

12. Cleary MA, Geiger E, Grady C, Best C, Naito Y, et al. (2012) Vascular tissue engineering: the next generation. Trends Mol Med 18: 394-404.

13. Greenwald SE, Berry CL (2000) Improving vascular grafts: the importance of mechanical and haemodynamic properties. J Pathol 190: 292-299.

14. Salacinski HJ, Goldner S, Giudiceandrea A, Hamilton G, Seifalian AM, et al. (2001) The mechanical behavior of vascular grafts: a review. J Biomater Appl 15: 241-278.

15. Davies MG, Hagen PO (1995) Pathophysiology of vein graft failure: a review. European Journal of Vascular and Endovascular Surgery9:7-18.

16. Teebken OE, Haverich A (2002) Tissue engineering of small diameter vascular grafts. Eur J Vasc Endovasc Surg 23: 475-485.

17. L'Heureux N, McAllister TN, de la Fuente LM (2007) Tissue-engineered blood vessel for adult arterial revascularization. N Engl J Med 357: 1451-1453.

18. Quint C, Arief M, Muto A, Dardik A, Niklason LE (2012) Allogeneic human tissue-engineered blood vessel. J Vasc Surg 55: 790-798.

19. Dahl SLM, Kypson AP, Lawson JH, Blum JL, Strader JT, et al. (2011) Readily Available Tissue-Engineered Vascular Grafts. Sci Transl Med3: $68 \mathrm{ra9}$.

20. Ferraresso M, Bertoli S, Nobili P, Bortolani EM (2013) Early experience with a newly developed electrospun polycarbonate-urethane vascular graft for hemodialysis access. J Vas Access14:252-256.

21. Veleva AN, Heath DE, Johnson JK, Nam J, Patterson C, et al. (2009) Interactions between endothelial cells and electrospun methacrylic terpolymer fibers for engineered vascular replacements. J Biomed Mater Res A 91: 1131-1139. 
Citation: Johnson J, Ohst D, Groehl T, Hetterscheidt S, Jones M (2015) Development of Novel, Bioresorbable, Small-Diameter Electrospun Vascular Grafts. J Tissue Sci Eng 6: 151. doi:10.4172/2157-7552.1000151

Page 7 of 7

22. Bergmeister H, Grasl C, Walter I, Plasenzotti R, Stoiber M, et al. (2012) Electrospun Small-Diameter Polyurethane Vascular Grafts: Ingrowth and Differentiation of Vascular-Specific Host Cells. Artif Organs 36:54-61.

23. McClure MJ, Sell SA, Ayres CE, Simpson DG, Bowlin GL (2009) Electrospinning-aligned and random polydioxanone-polycaprolactonesilk fibroin-blended scaffolds: geometry for a vascular matrix. Biomed Mater 4: 055010.

24. Fu W, Liu Z, Feng B, Hu R, He X, et al. (2014) Electrospun gelatin/PCL and collagen/PLCL scaffolds for vascular tissue engineering. Int J Nanomedicine 9: 2335-2344.

25. Du F, Wang H, Zhao W, Li D, Kong D, et al. (2012) Gradient nanofibrous chitosan/poly epsilon-caprolactone scaffolds as extracellular microenvironments for vascular tissue engineering Biomaterials33:762-770.

26. Drilling S, Gaumer J, Lannutti J (2009) Fabrication of burst pressure competent vascular grafts via electrospinning: effects of microstructure. J Biomed Mater Res A 88: 923-934.

27. Han N, Johnson JK, Bradley PA, Parikh KS, Lannutti JJ, et al. (2012) Cell attachment to hydrogel-electrospun fiber mat composite materials. J Funct Biomater 3: 497-513.

28. Hasan A, Memic A, Annabi N, Hossain M, Paul A, et al. (2014) Electrospun scaffolds for tissue engineering of vascular grafts. Acta Biomater 10: 11-25.
29. Nezarati RM, Eifert MB, Dempsey DK, Cosgriff-Hernandez E (2015) Electrospun vascular grafts with improved compliance matching to native vessels. Journal of Biomedical Materials Research Part B: Applied Biomaterials 103:313-323.

30. Bergmeister H, Schreiber C, Grasl C, Walter I, Plasenzotti R, et al. (2013) Healing characteristics of electrospun polyurethane grafts with various porosities. Acta Biomater 9: 6032-6040.

31. Raghavan ML, Vorp DA (2000) Toward a biomechanical tool to evaluate rupture potential of abdominal aortic aneurysm: identification of a finite strain constitutive model and evaluation of its applicability. J Biomech 33: 475-482.

32. Vorp DA, Schiro BJ, Ehrlich MP, Juvonen TS, Ergin MA, et al. (2003) Effect of aneurysm on the tensile strength and biomechanical behavior of the ascending thoracic aorta. Ann Thorac Surg 75: 1210-1214.

33. Huynh T, Abraham G, Murray J, Brockbank K, Hagen PO, et al. (1999) Remodeling of an acellular collagen graft into a physiologically responsive neovessel. Nat Biotechnol 17: 1083-1086.

34. Johnson J, Ghosh A, Lannutti J (2007) Microstructure-property relationships in a tissue-engineering scaffold. Journal of Applied Polymer Science104:2919-2927.

35. Johnson J, Niehaus A, Nichols S, Lee D, Koepsel J, et al. (2009) Electrospun PCL in vitro: a microstructural basis for mechanical property changes. J Biomater Sci Polym Ed 20: 467-481. 